\title{
O IDEB como política de regulação do Estado e legitimação da qualidade: em busca de significados
}

Andréia Melanda Chirinéa ${ }^{a, b}$ Carlos da Fonseca Brandão a,c

\section{Resumo}

Este trabalho procura discutir a qualidade da educação básica, legitimada pela avaliação externa e divulgada pelo Índice de Desenvolvimento da Educação Básica (IDEB). Esse índice combina o desempenho dos alunos na avaliação e o fluxo escolar, culminando no estabelecimento de um parâmetro objetivo (nota), que pretende refletir a qualidade educacional brasileira. As argumentações partem da premissa de que estes dois elementos são incipientes para determinar a qualidade educacional do país, na medida em que não se levam em conta os demais fatores que incidem sobre a qualidade, quais sejam: nível socioeconômico e cultural dos alunos; formação docente; valorização do magistério; condições materiais e imateriais de trabalho; gestão escolar; infraestrutura da escola, e insumos, entre outros. A reflexão que conduz ao debate sobre a insuficiência de elementos para estabelecer a qualidade da educação percorre os caminhos da avaliação externa no Brasil, da racionalidade técnica da gestão escolar referenciada primordialmente pelo IDEB e sua governabilidade, para atingir as metas determinadas pelo índice. Procura-se, com este ensaio, contribuir para o debate atual sobre o IDEB enquanto propositor e mobilizador de políticas nas escolas públicas brasileiras.

Palavras-chave: Gestão. Escola pública. Qualidade educacional. Avaliação externa.

\footnotetext{
a Universidade Estadual Paulista Júlio de Mesquita Filho - UNESP - Programa de Pós-graduação em Educação. Marília, São Paulo, Brasil.

b Universidade do Sagrado Coração - USC. Bauru, São Paulo, Brasil.

c Universidade Estadual Paulista Júlio de Mesquita Filho - UNESP - Departamento de Educação. Assis, São Paulo, Brasil.
} 


\section{Introdução}

Desde a década de 1990, quando as políticas e reformas educativas emergiram em quase todos os países da América Latina, inclusive no Brasil - as quais traziam em seu bojo a defesa do Estado mínimo, que deveria ter o máximo de eficiência -, as avaliações externas ganharam força e se tornaram arautos da qualidade educacional brasileira, tendo como consequência direta o estabelecimento de rankings com os melhores e piores resultados, tanto de sistemas de ensino como de escolas públicas e particulares.

A centralidade política e social que a avaliação externa ganhou nas últimas décadas é discutida por diversos autores (AFONSO, 2005; ARAÚJO; LUZIO, 2005; FRANCO; ALVES; BONAMINO, 2007; SOUSA; OLIVEIRA, 2010; WERLE, 2011; ALMEIDA; DALBEN; FREITAS, 2013). Estes estudos suscitam os caminhos percorridos pelas avaliações externas no Brasil, ao longo de mais de vinte anos, ao mesmo tempo em que procuram desvelar políticas educacionais e de organização do trabalho na escola, frente a uma nova governabilidade da educação pública e a um novo conceito de qualidade educacional, consubstanciado no IDEB (Índice de Desenvolvimento da Educação Básica).

Para Coelho (2008), a ineficiência do sistema escolar, bem como as novas exigências de qualificação e formação, aliadas à reestruturação do Estado brasileiro, foram os alicerces da implantação das avaliações externas no Brasil. No momento em que o Estado deixa de ser provedor para ser o regulador, as recomendações de agências internacionais, como o Banco Mundial, o Fundo Monetário Internacional e a Organização das Nações Unidas para a Educação, a Ciência e a Cultura, passam adequar o sistema escolar brasileiro a um modelo economicista, para atender às necessidades do mercado de trabalho.

A reforma do Estado Brasileiro procurou implantar uma administração mais gerencial e menos burocrática, como resposta a uma crise fiscal e estrutural, cujo objetivo era reduzir os custos do Estado e tornar mais eficiente sua administração. Entre os princípios da Nova Gestão Pública ou new public management, estão o fortalecimento do Estado, a sua regulação e a necessidade de adequar ações em prol de uma administração eficiente e voltada para o controle de resultados.

Portanto, a reforma do Estado tinha como princípio reorganizar as estruturas da administração pública, com vistas a qualidade e produtividade dos serviços 
prestados. Isto envolveria as funções de descentralização, regulação e coordenação do Estado.

Cabe ressaltar que a reforma do Estado, proposta na década de 1990, vai delinear as políticas educacionais no Brasil, na medida em que propõe a avaliação externa como mecanismo de controle e regulação do Estado.

Diante desse quadro, a concepção de qualidade de ensino passou a ser significativamente pautada pelas notas e pelos resultados obtidos por meio das avaliações externas, como, por exemplos, o SAEB e a Prova Brasil. Estas avaliações têm, por um lado, o objetivo de mensurar habilidades cognitivas dos estudantes em conteúdos pertinentes às áreas de Língua Portuguesa e Matemática, e, por outro lado, o objetivo de oferecer um indicativo sobre a possível qualidade de ensino que é ministrado nas escolas, subsidiando, desta forma, a tomada de decisões da gestão escolar.

É dentro desse contexto - e também como consequência direta desse processo que é criado o Índice de Desenvolvimento da Educação Básica (IDEB), indicador do Ministério da Educação (MEC), elaborado pelo Instituto Nacional de Estudos e Pesquisas Educacionais “Anísio Teixeira” (INEP), que reúne os dados do SAEB e da Prova Brasil, e as taxas de aprovação, reprovação e evasão, obtidas por meio dos dados sistematizados do Censo da Educação Básica. A combinação desses dados gera um parâmetro balizador de metas a serem atingidas, com o propósito de monitorar e avaliar o sistema educacional do país, assim como assegurar a melhoria na qualidade da educação.

O IDEB é parte integrante do Plano de Desenvolvimento da Educação (PDE) e do Plano de Metas Compromisso Todos pela Educação (Decreto n. ${ }^{\circ}$ 6.094/07), dispositivo legal que coloca em ação as 28 propostas contidas no $\mathrm{PDE}$, cujo eixo principal é a qualidade educacional, bem como a mobilização social para atingir as metas estabelecidas pelo plano. Para tanto, empreende-se uma articulação entre União, Estados, Distrito Federal, Municípios e sociedade civil em prol da qualidade da educação. Segundo o Art. 1. ${ }^{\circ}$ do Decreto 6.094:

O Plano de Metas Compromisso Todos pela Educação (Compromisso) é a conjugação dos esforços da União, Estados, Distrito Federal e Municípios, atuando em regime de colaboração, das famílias e da comunidade, em proveito da melhoria da qualidade da educação básica (BRASIL, 2007). 
Neste sentido, cada ente federado assume voluntariamente o compromisso e a responsabilidade de promover a melhoria da qualidade da educação básica em sua esfera de competência, mediante meta estabelecida pelo IDEB (BRASIL, 2007).

A proposta oficial é coibir a reprovação indiscriminada e estabelecer metas para os sistemas de ensino e as escolas, numa mobilização pela qualidade da educação, para que, em 2021, o país atinja a meta de qualidade educacional dos países desenvolvidos (HADDAD, 2008).

O IDEB, portanto, passou a ser, além de propositor de políticas públicas, o indutor de ações das escolas e dos sistemas de ensino para efetivação da qualidade. Embora seja um indicador de resultado, e não de qualidade, é a partir deste - e da divulgação dos seus resultados - que se mobilizam ações para melhoria da qualidade.

\section{Referencial de qualidade legitimada pela avaliação externa}

Segundo alguns teóricos (BRUNO, 1996; OLIVEIRA, 1996; SOUZA, 1997), a busca da qualificação da escola está ligada à reestruturação capitalista e à lógica da produtividade, uma vez que, numa sociedade globalizada e tecnológica, o foco do processo produtivo passa a ser o intelecto e não a força. Nesse sentido, é preciso investir na qualificação do sistema de ensino, a fim de formar cidadãos capacitados para atender às necessidades emanadas pelo mercado. Portanto, a busca da qualidade na educação não é referência para a consolidação do direito do cidadão em exercer sua participação política e social. A busca da qualidade está muito mais ligada ao desenvolvimento econômico do país, bem como sua inserção no grupo dos países desenvolvidos.

Partindo dessa premissa, Souza (1997, p. 264) esclarece que "[...] a educação precisa alcançar qualidade capaz de responder às demandas decorrentes das transformações globais nas estruturas produtivas e do desenvolvimento tecnológico". Ainda segundo essa mesma autora, as avaliações legitimam a qualidade nos processos educativos e nas escolas, pois funcionam como instrumentos de medida, adequação e controle dos sistemas educativos, passando a orientar políticas públicas na área da educação. 
A qualidade, portanto, emerge da necessidade de se prepararem os indivíduos para processos mentais cada vez mais requintados e abstratos, qualificando-os para o pleno exercício de uma profissão no mercado de trabalho. A qualidade, nesse sentido, não é uma qualidade que emerge do núcleo formador da escola e dos sistemas de ensino como direito do cidadão, mas uma qualidade concebida por agências multilaterais, com o propósito de diminuir a taxa de pobreza dos países em desenvolvimento e de adequar a educação a uma reestruturação produtiva do capitalismo, no qual a educação ganha papel central, ao ser considerada uma condição geral de produção.

Contribuindo para esse argumento, Afonso (2005) entende que a responsabilidade maior não recai sobre os governos e as políticas públicas, mas sobre as escolas e os sistemas de ensino. Nesse sentido, o autor alega que se cria, a partir da responsabilização das escolas e dos sistemas de ensino, um ethos competitivo, baseado na lógica do mercado.

[...] desta ideologia da privatização, ao enaltecer o capitalismo de livre mercado, conduziu a alterações e mudanças fundamentais no papel do Estado, tanto ao nível local como ao nível nacional. Neste sentido [...] diminuir as despesas públicas exigiu não só a adopção de uma cultura gestinonária ou gerencialista no setor público, como também induziu a criação de mecanismos de controlo e responsabilização mais sofisticados. A avaliação aparece assim como um pré-requisito para que seja possível a implementação desses mecanismos (AFONSO, 2005, p. 49).

Essa situação colabora para que ocorram rápidas tentativas de adequações dos processos de gestão da escola pública baseada, agora, numa perspectiva neoliberal e nos modelos de gestão privada, cujos parâmetros de eficiência, eficácia e produtividade, originários da economia de mercado e internalizados pelos sistemas escolares, são os grandes fatores considerados como qualitativos nos processos educativos. Para tanto, cabe à escola modificar seu conteúdo cultural, em prol de uma formação que atenda aos objetivos do mercado.

No entendimento de Azevedo (2007) e de Lima (2008), esse processo nada mais é do que uma forma direta de mercantilização da educação, na medida em que se compara e se administra uma instituição escolar, com valores próprios de uma empresa privada, especialmente com a predominância de valores econômicos. 
Historicamente, essa situação não se constitui em uma novidade. No início da década de 1960, a então Lei de Diretrizes e Bases da Educação Nacional n. ${ }^{\circ} 4.024 / 61$, diante de um contexto econômico e político caracterizado pelo desenvolvimentismo do governo Juscelino Kubitschek, já estabelecia, no seu artigo 96, que a qualidade da educação deveria estar fundamentada na produtividade. Cabe ressaltar que, naquele momento histórico, o país vivia uma fase de internacionalização da economia e progresso acelerado. Textualmente, o artigo 96 da Lei n. ${ }^{\circ} 4.024 / 61$, determinava que:

O Conselho Federal de Educação e os conselhos estaduais de educação na esfera de suas respectivas competências, envidarão esforços para melhorar a qualidade e elevar os índices de produtividade do ensino em relação ao seu custo: a. Promovendo a publicação anual das estatísticas do ensino e dados complementares, que deverão ser utilizados na elaboração dos planos de aplicação de recursos para o ano subseqüente; b. Estudando a composição de custos do ensino público e propondo medidas adequadas para ajustá-los ao melhor nível de produtividade (BRASIL, 1961).

Assim, podemos notar que o trinômio ensino-qualidade-produtividade, tendo como referência o conceito econômico de relação custo/benefício, já se fazia presente, formal e legalmente, na primeira LDB brasileira; porém, só a partir da década de 1980, especialmente em sua segunda metade (com a promulgação da nova Constituição brasileira, em 1988) é que foi dada uma maior ênfase a essas questões.

A qualidade educacional e a estratégia de avaliar os processos educativos por meio de avaliações de larga escala estão também contemplados na Constituição Federal de 1988, nos artigos 206 e 209. O artigo 206 da Carta Magna estabelece a garantia de padrões de qualidade como dever do Estado e como uma das diretrizes da educação brasileira. Já o artigo 209, por sua vez, determina que o Poder Público deve realizar avaliações dos seus respectivos sistemas de ensino, com o intuito de mensurar a qualidade dos mesmos.

Entretanto, para Pinto (2008), embora a legislação contemple a qualidade da educação, estabelecendo, para os sistemas de ensino, preceitos legais que a garantam, a realidade está longe de ser cumprida, porque, enquanto as escolas particulares preparam suas crianças e seus jovens para o ensino superior, a escola 
pública não consegue garantir domínios mínimos de leitura, escrita e cálculo. No que se refere à aferição da qualidade, o autor explica que:

O atual sistema chamado de avaliação [...], mas que na verdade não passa de um conjunto de testes padronizados de português e matemática, é claramente insuficiente para aferir a qualidade da educação oferecida pelos sistemas de ensino, mesmo considerando os limites dos objetivos postos pela legislação. (PINTO, 2008, p. 59).

$\mathrm{O}$ autor trabalha com a hipótese de que quanto mais insumos - entendidos como recursos humanos bem formados, recursos materiais em quantidade suficiente, infraestrutura adequada das próprias escolas, etc. -, maior será a qualidade do ensino ofertado por essa escola e, por conseguinte, melhor será o desempenho dos estudantes nos testes padronizados presentes nas avaliações de larga escala. Portanto, para esse autor, não existe qualidade sem infraestrutura, equipamentos, laboratórios de informática com acesso à internet, bibliotecas, remuneração de professores, ou seja, não existe qualidade na escola, porque não há insumos suficientes (e de qualidade) para alcançá-la.

Assim, podemos afirmar que educação de qualidade custa caro e que, por mais que o Estado exerça suas diferentes formas de pressão sobre as escolas - umas mais diretas (leis e decretos, por exemplo), outras mais indiretas (como, por exemplo, pela intensa difusão de conceitos como descentralização, democratização, flexibilização, autonomia, participação, etc.) - ou proponha estímulos pecuniários, por meio da remuneração por competência avaliada com base na produtividade e certificações, e por meio de bônus vinculados aos resultados do IDEB e IDESP, o que define a qualidade nos processos educativos é o investimento massivo na qualidade da formação dos professores (inicial e continuada), melhoria nas condições de trabalho, salários dignos e infraestrutura adequada à excelência dos processos educativos.

Há de se ressaltar ainda que entendemos que a avaliação se constitui em uma condição necessária à melhoria da qualidade de ensino no país, principalmente na escola pública. No entanto, as questões de qualidade, sua busca e melhoria devem emergir do núcleo da própria escola e dos que dentro desta atuam e frequentam, exigindo do Estado, enquanto propositor e regulador de políticas, as condições acima referidas para que haja a efetiva qualificação das escolas e dos sistemas de ensino. 


\section{A avaliação em foco e os caminhos percorridos pelas provas ANEB e ANRESC no Brasil}

No Brasil, os mecanismos de aferição da qualidade educacional tiveram início no final da década de 1980. Em 1987, o Ministério da Educação instituiu o Sistema Nacional do Ensino Público do $1 .^{\circ}$ grau (SAEP), como uma das exigências do Banco Mundial, para prover financiamentos para projetos educacionais a serem executados no Brasil. Em 1990, o SAEP foi substituído pelo Sistema de Avaliação da Educação Básica (SAEB), com o objetivo de monitorar o sistema e subsidiar políticas públicas para a área da educação (COELHO, 2008).

No entanto, algumas ações já haviam sido empreendidas desde 1906, quando houve a elaboração do Anuário Estatístico do Brasil, que exigia medições sobre número de escolas, professores, matrículas e repetências dos níveis superior, profissional, secundário e primário, das esferas públicas e privadas da educação brasileira. Em princípio, essa medida era executada somente no Rio de Janeiro, ou seja, na sede do Distrito Federal. Essas medições foram realizadas no período de 1906 a 1918, sendo retomadas somente em 1936, já com informações envolvendo todo o território nacional (HORTA NETO, 2007).

\section{ANEB e ANRESC}

O Sistema de Avaliação da Educação Básica (SAEB) foi normatizado pela Portaria 931 de 21 de março de 2005. É composto por duas provas complementares: a Avaliação Nacional da Educação Básica (ANEB), que avalia as competências cognitivas e habilidades utilizadas pelos alunos no processo de construção do conhecimento, e a Avaliação Nacional de Rendimento Escolar (ANRESC), cujo instrumento de avaliação é a Prova Brasil ${ }^{1}$.

O objetivo do SAEB é monitorar a qualidade na educação básica brasileira, tendo como referência instrumentos de coleta, como testes de conhecimentos de língua portuguesa e de matemática, e questionários socioeconômicos, a serem respondidos por alunos, professores, diretores e pelo responsável pela coleta de

\footnotetext{
${ }^{1}$ Enquanto o SAEB fornece médias de desempenho para o Brasil, regiões e unidades da Federação, assim como para cada um dos municípios e escolas participantes, a Prova Brasil, por sua vez, oferece resultados de desempenho apenas para o Brasil, regiões e unidades da Federação (SILVA, 2010). No portal do INEP (http://portal.inep.gov.br/web/prova-brasil-e-saeb) é possível consultar histórico, semelhanças e diferenças, resultados, questões das provas, além das legislações específicas de cada uma das avaliações (SAEB e Prova Brasil).
} 
dados. Além de monitorar a qualidade, o SAEB constitui um importante mecanismo de direcionamento das políticas públicas voltadas à qualidade, na medida em que fornece aos gestores dos sistemas de ensino informações relevantes para subsidiar decisões (HORTA NETO, 2007).

Os testes são aplicados, por amostragem, nos sistemas públicos e particulares de educação, contemplando estudantes do $5 .^{\circ}$ e do $9 .^{\circ}$ anos do ensino fundamental, e alunos do $3 .^{\circ}$ ano do ensino médio. Não fazem parte dessa população amostral os alunos que frequentam salas multisseriadas, classes de aceleração e classes de educação de jovens e adultos (ARAÚJO; LUZIO, 2005).

Além das provas de conhecimentos em português e matemática, também são aplicados questionários a professores, alunos e diretores das escolas, com o objetivo de identificar fatores que possivelmente influenciam o rendimento escolar e, consequentemente, a qualidade. Procura-se, com estes questionários, identificar o nível socioeconômico dos alunos, as rotinas de estudo, o perfil docente e dirigente, as condições de trabalho, a organização da escola e a estrutura física (SILVA, 2010).

Tais variáveis interferem sobremaneira na melhoria da qualidade, todavia não são explorados quando da definição de qualidade. Segundo apontamento demonstrado por Silva (2010, p. 434):

Apesar de o nível socioeconômico ser um determinante presente no questionário de contexto aplicado no Saeb, ele não é considerado a contento na constituição, divulgação e exploração dos indicadores de qualidade de ensino produzidos pelo governo e nem considerado seriamente na agenda de redefinição de políticas públicas [...] o que se percebe é que as notas referentes ao desempenho estudantil são supervalorizadas e destacadas enfaticamente em detrimento de outros determinantes de igual ou maior relevância na mensuração da qualidade do ensino.

Segundo Oliveira e Araújo (2005), os resultados do SAEB indicam que a maioria dos alunos das escolas públicas não atingem os padrões mínimos de conhecimentos nessas disciplinas e que, por outro lado, o desempenho dos alunos provenientes de escolas estaduais é, aproximadamente, o mesmo que o desempenho dos alunos provenientes de escolas municipais. Entretanto, alguns especialistas apontam que esses testes não revelam exatamente o diagnóstico do sistema educativo. 
Isso ocorre porque os resultados dos testes sofrem influência de variáveis, como o perfil socioeconômico da família e o nível de escolaridade dos pais. Esses são fatores inerentes ao processo de avaliação e que acabam interferindo em seus resultados.

Os dados do SAEB indicam o desempenho relativo dos alunos nos vários estados. $\mathrm{O}$ fato de um estado ou uma rede de ensino ter média superior a de outros estados ou redes significa que em média os alunos desse estado ou rede de ensino sabem mais do que os outros em relação às competências avaliadas. Mas isto não significa que o ensino seja melhor. Há outras variáveis que afetam os resultados escolares como educação dos pais, renda, nível socioeconômico (OLIVEIRA; SCHWARTZMAN, 2002, p. 27).

Já para o INEP, a análise dos resultados dos levantamentos do SAEB permite acompanhar a evolução do desempenho dos alunos e dos diversos fatores incidentes na qualidade e na efetividade do ensino ministrado nas escolas, possibilitando a definição de ações voltadas à correção das distorções identificadas e o aperfeiçoamento das práticas e dos resultados apresentados pelas escolas e pelos diferentes sistemas de ensino existentes no Brasil.

Assim, o SAEB acabou se tornando um importante sistema de avaliação educacional de larga escala do país; no entanto, para Silva (2010), é preciso definir com maior propriedade qual o objetivo final da avaliação e quais ações políticas serão incrementadas a partir do diagnóstico apontado pela prova. Neste sentido, segundo esse autor, cabe refletir qual é o uso social dos resultados apresentados pelo SAEB.

Nesta perspectiva, duas posições antagônicas podem ser discutidas: a primeira é considerar os resultados de desempenho como norteadores de políticas de melhoria da qualidade, partindo de uma reflexão da própria escola (autoavaliação). A segunda posição é pautar o SAEB como mobilizador da lógica meritocrática e um dos desdobramentos disso é considerar o conteúdo da avaliação como currículo oficial. Desta forma, os professores passam a ensinar os conteúdos escolares que são contemplados nos testes, além de treinarem os alunos para realização do exame. 
Tal evidência foi demonstrada por Souza e Oliveira (2003) em pesquisa realizada em cinco Estados da federação, cujo objetivo foi analisar como os resultados dos sistemas de avaliação destes Estados influenciam a formulação e a implementação de políticas educacionais.

Embora a implementação das avaliações externas esteja se consolidando cada vez mais no país, sendo estas utilizadas pela maioria das escolas públicas brasileiras, os resultados servem, por exemplo, para subsidiar ações da gestão escolar, como alocar os conteúdos das avaliações no currículo escolar; evitar a reprova dos alunos para que, de alguma forma, isso compense a nota da avaliação externa e não prejudique o IDEB, e ainda rever o próprio mecanismo de gestão, na perspectiva de uma autoavaliação. Neste sentido, o IDEB serve como indutor tanto de políticas públicas quanto de ações das secretarias de educação e da própria escola, para alcançar as metas estabelecidas pelo índice.

Enquanto o SAEB avalia por amostragem, a Prova Brasil caracteriza-se como uma avaliação censitária, ou seja, universal para todos os alunos matriculados nos 5. ${ }^{\circ}$ e 9. ${ }^{\circ}$ anos do Ensino Fundamental público, privado ou federal (SILVA, 2010).

A Prova Brasil - ou Avaliação Nacional de Rendimento Escolar - foi um instrumento de avaliação externa criado pelo MEC/INEP em 2005, com o objetivo de avaliar o desempenho dos estudantes das escolas de nível fundamental urbanas, nas áreas de Língua Portuguesa, com foco na leitura, e Matemática. A Prova Brasil é mais detalhada, uma vez que agrega todas as escolas, sem exceção, complementando a avaliação realizada pela Avaliação Nacional da Educação Básica (SILVA, 2010).

Já o IDEB, Índice de Desenvolvimento da Educação Básica, foi um mecanismo criado pelo INEP para ser um indicador sintético da educação brasileira, que leva em consideração resultados acadêmicos e fluxo escolar, obtidos por meio da Prova Brasil, do SAEB e do Censo Escolar (FERNANDES, 2007). O princípio do IDEB é que o aluno aprenda e avance para as séries seguintes. Seu cálculo é feito da seguinte forma (Equação 1):

$\operatorname{IDEB}=(1 / \mathrm{T}) \cdot \mathrm{N}($ nota $)$

Em que:

$\mathrm{T}=$ número de anos que, em média, os alunos gastam para completar uma série $(\mathrm{T}=$ tempo). Quando esse fluxo é feito adequadamente (1/T), o IDEB equivale ao valor da nota, e sua tendência é manter-se estável ou aumentar. Mas quando o fluxo é interrompido por repetência, evasão ou abandono, T assumirá valores maiores e, consequentemente, o índice tende a diminuir, comprometendo a nota final. 
$\mathrm{N}$ = média das avaliações externas, ou seja, o valor do desempenho dos estudantes no SAEB e na Prova Brasil, expressa em valores que vão de 0 a 10.

Logo, os referenciais 'tempo de estudo' e 'nota de desempenho dos estudantes nos exames padronizados' são os dados quantitativos que formam o IDEB (FRANCO; ALVES; BONAMINO, 2007).

A compilação desses dados resulta em uma média para as Unidades da Federação e para as próprias escolas, gerando gráficos informacionais sobre o nível de qualidade de cada escola e de cada sistema de ensino (FERNANDES, 2007). Assim, o IDEB se constitui no principal indicador objetivo utilizado para monitorar a qualidade da educação básica no país.

Para alcançar as metas propostas pelo IDEB, é preciso que escolas e sistemas de ensino regularizem o fluxo escolar, ou seja, quanto menores a reprovação e o abandono de alunos, melhor a nota do índice. Outra exigência para aumentar o valor da nota é a melhoria do desempenho dos alunos nas avaliações externas.

A média nacional da aferição do IDEB no ano de 2005 foi de 3,8. Já no ano de 2007, o resultado ficou em 4,2 e, em 2009, o IDEB para as séries iniciais do Ensino Fundamental alcançou nota 4,6.

Percebe-se, portanto, um resultado crescente do IDEB ao longo das aplicações das provas ANEB e ANRESC. A meta assumida pelo IDEB é alcançar nota 6 em 2021, quando o Brasil estará às vésperas de completar 200 anos de sua independência. Uma vez atingidos os objetivos, o país então poderá integrar o grupo dos países que fazem parte da Organização para a Cooperação e o Desenvolvimento Econômico (OCDE) (HADDAD, 2008).

De acordo com as notas obtidas pelo IDEB, é possível realizar projeções, conforme indica a Tabela 1, tendo em vista que a expectativa é de que o Brasil passará a fazer parte do grupo dos países mais desenvolvidos do mundo, até 2021.

Ao levar em consideração indicadores de fluxo e rendimento escolares, o IDEB das escolas alcançará notas altas, simplesmente por não reter os estudantes, sem que isso signifique, de fato, qualidade nos processos educativos.

Outra estratégia utilizada pelas escolas é o treinamento dos estudantes para realização da avaliação. Neste caso, evidenciam-se, nas ações da gestão escolar, 
Tabela 1 - Notas do IDEB 2005, 2007, 2009, 2011, 2013 e projeções para o Brasil

\begin{tabular}{|c|c|c|c|c|c|c|c|c|c|c|}
\hline \multicolumn{11}{|c|}{ Anos Iniciais do Ensino Fundamental } \\
\hline & \multicolumn{5}{|c|}{ IDEB Observado } & \multicolumn{5}{|l|}{ Metas } \\
\hline & 2005 & 2007 & 2009 & 2011 & 2013 & 2007 & 2009 & 2011 & 2013 & 2021 \\
\hline Total & 3,8 & 4,2 & 4,6 & 5,0 & 5,2 & 3,9 & 4,2 & 4,6 & 4,9 & 6,0 \\
\hline \multicolumn{11}{|c|}{ Dependência Administrativa } \\
\hline Estadual & 3,9 & 4,3 & 4,9 & 5,1 & 5,4 & 4,0 & 4,3 & 4,7 & 5,0 & 6,1 \\
\hline Municipal & 3,4 & 4,0 & 4,4 & 4,7 & 4,9 & 3,5 & 3,8 & 4,2 & 4,5 & 5,7 \\
\hline Privada & 5,9 & 6,0 & 6,4 & 6,5 & 6,7 & 6,0 & 6,3 & 6,6 & 6,8 & 7,5 \\
\hline Pública & 3,6 & 4,0 & 4,4 & 4,7 & 4,9 & 3,6 & 4,0 & 4,4 & 4,7 & 5,8 \\
\hline \multicolumn{11}{|c|}{ Anos Finais do Ensino Fundamental } \\
\hline & \multicolumn{5}{|c|}{ IDEB Observado } & \multicolumn{5}{|l|}{ Metas } \\
\hline & 2005 & 2007 & 2009 & 2011 & 2013 & 2007 & 2009 & 2011 & 2013 & 2021 \\
\hline Total & 3,5 & 3,8 & 4,0 & 4,1 & 4,2 & 3,5 & 3,7 & 3,9 & 4,4 & 5,5 \\
\hline \multicolumn{11}{|c|}{ Dependência Administrativa } \\
\hline Estadual & 3,3 & 3,6 & 3,8 & 3,9 & 4,0 & 3,3 & 3,5 & 3,8 & 4,2 & 5,3 \\
\hline Municipal & 3,1 & 3,4 & 3,6 & 3,8 & 3,8 & 3,1 & 3,3 & 3,5 & 3,9 & 5,1 \\
\hline Privada & 5,8 & 5,8 & 5,9 & 6,0 & 5,9 & 5,8 & 6,0 & 6,2 & 6,5 & 7,3 \\
\hline Pública & 3,2 & 3,5 & 3,7 & 3,9 & 4,0 & 3,3 & 3,4 & 3,7 & 4,1 & 5,2 \\
\hline \multicolumn{11}{|c|}{ IDEB Ensino Médio } \\
\hline & \multicolumn{5}{|c|}{ IDEB Observado } & \multicolumn{5}{|l|}{ Metas } \\
\hline & 2005 & 2007 & 2009 & 2011 & 2013 & 2007 & 2009 & 2011 & 2013 & 2021 \\
\hline Total & 3,4 & 3,5 & 3,6 & 3,7 & 3,7 & 3,4 & 3,5 & 3,7 & 3,9 & 5,2 \\
\hline \multicolumn{11}{|c|}{ Dependência Administrativa } \\
\hline Estadual & 3,0 & 3,2 & 3,4 & 3,4 & 3,4 & 3,1 & 3,2 & 3,3 & 3,6 & 4,9 \\
\hline Privada & 5,6 & 5,6 & 5,6 & 5,7 & 5,4 & 5,6 & 5,7 & 5,8 & 6,0 & 7,0 \\
\hline Pública & 3,1 & 3,2 & 3,4 & 3,4 & 3,4 & 3,1 & 3,2 & 3,4 & 3,6 & 4,9 \\
\hline
\end{tabular}

Fonte: Brasil (2013).

os procedimentos de ressignificação das avaliações externas, ou seja, a adaptação do ambiente escolar e dos conteúdos curriculares, na busca de demonstrar o atributo ou o suposto nível de qualidade de cada estabelecimento.

O IDEB é um indicador importante na medida em que demonstra fragilidades nas escolas brasileiras relacionadas a fluxo e desempenho escolar; no entanto, é insuficiente para medir a qualidade da educação por restringir-se apenas a essas duas variáveis, desconsiderando outros aspectos igualmente importantes para a qualidade, como a cultura organizacional da escola, a prática docente, o nível socioeconômico e cultural das famílias, e o estilo de gestão e liderança.

Atualmente, o índice é considerado o grande termômetro da qualidade da educação brasileira. No entanto, este demonstra apenas dados estatísticos ou 
quantitativos. Não obstante, coíbe as escolas a se adequarem a determinadas normas de condutas, principalmente da gestão escolar, para atingir notas cada vez mais altas no IDEB e alcançar expectativas pré-definidas de desempenho escolar (CHIRINÉA, 2010).

Uma pesquisa realizada no ano de 2010, comparando duas escolas - uma com maior $(8,2)$ e outra com menor $(2,4)$ IDEB - demonstrou que o tipo de gestão da escola, o clima organizacional e o sentimento de pertencimento dos professores são condições que favorecem a qualidade. Além dessas dimensões, evidenciou-se que a condição socioeconômica e cultural dos estudantes e de suas famílias também constitui fator determinante para a qualidade da educação. Tais dimensões não são consideradas na composição da nota do IDEB, tampouco nos resultados apresentados (CHIRINÉA, 2010).

Evidencia-se, portanto, que, além dos referenciais de fluxo e desempenho, há outros atributos ou fatores que contribuem para a qualidade da educação, mas que são negligenciados pela avaliação externa.

Enquanto indicador de resultado e não de qualidade, o IDEB se mostra incapaz de retratar de forma completa a realidade das instituições escolares, porque existem outras variáveis que interferem na qualidade da educação, como: gestão escolar; formação e condições de trabalho dos professores; ambiente educativo; prática pedagógica e de avaliação, e acesso e permanência na escola. A qualidade, neste sentido, não é um fator estanque e não pode ser buscada somente com testes que medem o conhecimento cognitivo dos alunos.

Tais variáveis conduzem ou contribuem para a qualidade da educação. O tamanho da escola, por exemplo, faz diferença em termos qualitativos. Escolas menores são mais fáceis de gerenciar. Escolas com equipes mais estáveis e menor índice de absenteísmo dos professores tendem a apresentar melhores resultados em termos de qualidade. O perfil do diretor e seu tipo de gestão podem influenciar a qualidade dos processos educativos (PINTO, 2008).

Para a qualidade da educação escolar se constituir, é preciso considerar insumos internos e externos, bem como seus processos no interior das unidades escolares. O conceito de qualidade não pode ser reduzido somente ao desempenho escolar, tampouco ser tomado como referência para um processo de prestação de contas (accountability) e para construção de um ranking entre as escolas.

As avaliações externas são necessárias na medida em que auxiliam a reflexão da própria escola sobre suas fragilidades. O que é questionável é o uso estatístico 
que se faz das avaliações externas como mecanismos de coerção do Estado para atingir metas de qualidade e produtividade na educação brasileira, sob o pretexto de medir a qualidade da educação. Dessa maneira, concorda-se com Castro (2009, p. 34), quando ela afirma que:

[...] os testes padronizados são instrumentos necessários, mas insuficientes para avaliar a melhora da qualidade da educação, principalmente os testes como SAEB e o Enem, adotados pelas políticas públicas, pois possuem um caráter restrito de avaliação. É importante considerar, nesse processo, não só os insumos, mas também outros indicadores como a cultura organizacional da escola, as práticas e as relações entre professores e alunos.

Entende-se, portanto, que, sem uma reflexão da própria escola sobre suas potencialidade e fragilidades, a avaliação externa se reduz à mera atividade técnica e mecanicista, cujos critérios de eficiência, eficácia e produtividade acabam por direcionar todo o processo educativo.

Esses critérios restringem o processo didático-pedagógico em detrimento do resultado final alcançado pela escola no IDEB, através apenas do desempenho estudantil, apresentado em dados quantitativos.

\section{Em busca de significados: O IDEB enquanto indicador de resultados e não de qualidade}

Durante muito tempo, os problemas da educação brasileira foram sendo mantidos num constante "jogo" de tensões entre duas vertentes. De um lado, as questões pedagógicas próprias da educação formal e, consequentemente, da escola, e de outro lado, os fatores sociais. Nenhum dos dois lados assume isoladamente a responsabilidade pela produção do fracasso escolar ou pela baixa qualidade da educação brasileira.

Freitas (2007) argumenta que as duas vertentes são responsáveis, em conjunto, no coletivo e de forma dialética. Por isso, somente a responsabilização da escola pelo sucesso ou fracasso escolar, baseado no IDEB, sem levar em consideração outras variáveis que interferem no processo e que são relegadas ou negligenciadas pelo índice, pode comprometer o resultado. 
Ainda segundo Freitas (2007), algumas dessas variáveis são deixadas de fora no processo das melhores e piores escolas ranqueadas pelo IDEB, como estas: questões como absenteísmo de professores e sua carga horária, tipo de gestão escolar, número de alunos na sala de aula, além do nível socioeconômico e cultural das famílias, cujos filhos frequentam a escola pública. Na opinião do autor:

Diante deste quadro, escolher apenas uma variável, desempenho do aluno, para analisar a educação básica brasileira, como o IDEB faz, é certamente temerário em face deste complexo de variáveis (FREITAS, 2007, p. 972).

O autor ainda adverte que a ideia de regulação da qualidade, por meio de testes padronizados, vem ganhando força no Brasil, como se fosse possível "monitorar" escolas com realidades tão específicas. Nesse sentido, entende-se que escolas e sistemas de ensino, principalmente os municipais, sentindo a pressão imposta pelas avaliações externas, contratam grandes grupos educacionais para se enquadrar nas exigências impostas pelos testes ou, no limiar de uma saída "estratégica", para burlar o IDEB, treinam os alunos para a realização das provas ou utilizam outros meios, mais criativos e menos ortodoxos, como, por exemplo, induzir os alunos que apresentam maiores dificuldades de aprendizagem a faltar no dia de aplicação das avaliações ou reprová-los para que não cheguem aos $5 .^{\circ} \mathrm{e} 9 .^{\circ}$ anos do Ensino Fundamental, no período de realização das provas.

A qualidade, portanto, não emerge da própria escola e de sua construção coletiva, consubstanciada no Projeto Político-Pedagógico, "[...] a qualidade é vista como objeto de medida de desempenho como eficiência do sistema de ensino e não como igualdade de resultados dos alunos matriculados nesse sistema" (FREITAS, 2007, p. 974).

Na mesma perspectiva, Paro (2001) entende que não há na escola um padrão único de aferição de sua qualidade, até porque não há previsão dos insumos (alunos) que entram no sistema escolar, tampouco um acompanhamento dos egressos deste sistema. Avaliar a qualidade da escola sob essa perspectiva requer definir padrões de um bom ensino, como sinônimo de um bom processo e, portanto, garantia de um bom produto, que é o próprio aluno, após sua etapa de escolarização.

Azevedo (2007) também condena a avaliação centrada nos "produtos", ignorando os processos e "coisificando" o conhecimento. Segundo o autor, a função da avaliação externa é quantificar, mensurar, padronizar e, após tudo isso, elaborar escalas de competição entre as escolas. $\mathrm{O}$ fato é que esse tipo de avaliação 
desconhece a complexidade dos processos educacionais. Os parâmetros buscados são o da eficiência, eficácia e produtividade. Segundo Azevedo (2007, p. 10):

O conhecimento é reduzido à sua dimensão cognitiva, traduzido em acúmulos quantitativos, mensuráveis, como se fosse possível separá-lo das relações ricas e complexas entre educador, educando, desvinculá-lo do emaranhado que tece os laços da instituição escola com valores éticos e culturais que compõem os contextos educativos.

Nóvoa (1995) entende que as instituições de ensino possuem especificidades muito particulares, não podendo ser pensadas ou administradas com alto grau de racionalidade, como acontece com as empresas. Segundo o autor, as mudanças na sociedade exigem mudanças também na escola. Todavia, é preciso pensar essas mudanças sob o ponto de vista da complexidade técnica, científica e humana, próprio das instituições de ensino.

Na opinião de Lima (2008), a avaliação em larga escala centra-se somente nos resultados observáveis e que podem ser medidos, todavia, numa ação que tramita de fora para dentro da escola, sem que se levem em conta as questões culturais ou subjetivas do processo. Segundo Lima (2008, p. 131):

Convoca-se uma mono-racionalidade de tipo técnico e uma perspectiva gestionária-utilitária (neo-tayloriana), decompõese e fragmenta-se o processo de avaliação, quantificando, mensurando, formalizando; adopta-se uma visão mecanicista da organização escolar, centrada nas operações técnicas, na eficácia e na eficiência.

Castro $(2009$, p. 31) também argumenta que as avaliações externas, como o $\mathrm{SAEB}$, o Enem ${ }^{2}$ e o Enade $^{3}$, constituem um referencial vago e inadequado para a qualidade na educação. Segundo essa autora,

Essas avaliações baseadas em indicadores de desempenho mostram-se restritas e inadequadas para medir a qualidade efetiva da educação, pois não ultrapassam o nível instrumental. Fundamentam-se em pressupostos técnicos que se distanciam

\footnotetext{
2 ENEM - Exame Nacional do Ensino Médio.

${ }^{3}$ ENADE - Exame Nacional de Desempenho de Estudantes.
} 
de juízo de valor, do compromisso com a justiça social, bem como das ações e dos interesses dos sujeitos que, concretamente, a definem e a adotam.

Conclui-se, portanto, que os fatores considerados qualitativos são aqueles preconizados pelas políticas neoliberais de adequação de escolas e sistemas de ensino para formar e qualificar o "capital humano", seja sob o ponto de vista de qualificação para o mercado, seja sob a perspectiva de fornecer condições iguais para que todos aprendam e tenham oportunidade de alcançar lugares mais valorizados na sociedade. Para tanto, cabe às políticas públicas exercerem certa pressão nas escolas e nos sistemas de ensino, a fim de aumentar a eficácia e a eficiência dos processos educativos.

As ferramentas para a consolidação dessas políticas se fazem por meio de mecanismos engendrados que conduzem à qualidade, do ponto de vista quantitativo, como os méritos, os rankings, o bônus vinculado à produtividade e os prêmios financeiros destinados àquelas instituições que apresentarem os melhores resultados e, consequentemente, o melhor índice.

Não obstante, cabe ressaltar que, para além do aspecto pedagógico e dos saberes cognitivos mensurados na avaliação externa e demonstrados pelo IDEB, há outros fatores que, quando mobilizados, direcionam a melhoria da qualidade de ensino e, consequentemente, dos resultados do IDEB. Esses fatores fazem a diferença numa unidade escolar e não podem ser desprezados.

Segundo Ball (2001), Souza e Oliveira (2003) e Afonso (2005), o IDEB funciona como uma espécie de quase mercado educacional, na medida em que se insere hoje como parâmetro de qualidade na área educacional ao eleger e diferenciar escolas e sistemas de ensino, promovendo inclusive a competição entre as escolas. Isso ocorre porque, após a divulgação de seus dados pela mídia e pelos órgãos oficiais, elege-se a melhor escola, assim como a pior, funcionando, portanto, como um marketing educacional ${ }^{4}$.

\section{Considerações finais}

Entendemos que a avaliação externa e, consequentemente, o IDEB se caracterizam como propositores de políticas públicas do Estado para mobilizar ações de melhoria

\footnotetext{
${ }^{4}$ Geralmente, os rankings com as melhores escolas são elaborados e divulgados pelos meios de comunicação em massa.
} 
para o setor educacional, definindo prioridades a partir dos dados coletados. No entanto, essa racionalidade do Estado se manifesta somente nos dados estatísticos apresentados no momento de divulgação do IDEB, pois ações e propostas de melhoria da qualidade educacional - como valorização docente, piso salarial compatível com a função, redução do número de estudantes por sala, bibliotecas e salas de informática bem equipadas, cursos de formação e aperfeiçoamento para os professores, e aumento do valor de financiamento da educação - não são comumente implantadas pelo Estado, a partir da apresentação dos índices. Outro fator desconsiderado pelo índice, em sua composição, é o nível socioeconômico dos estudantes que prestam tais avaliações.

A complexidade do processo educativo não pode ser reduzida a alguns produtos que podem ser mensuráveis ou visíveis, e que servem para fornecer resultados significativos por meio de testes padronizados. Essas medidas tornam a perspectiva da qualidade educacional limitada, por não considerar outros fatores além do desempenho estudantil. Possuem, portanto, um caráter reducionista.

A avaliação externa é importante, na medida em que informa escolas e sistemas de ensino sobre uma dada realidade para a tomada de decisões; no entanto, é preciso repensar seu escopo e aliá-la a uma autoavaliação institucional e ao diagnóstico das fragilidades, com a perspectiva de articulação entre as esferas macro, meso e micro do processo de avaliação, e o replanejamento de políticas e ações que efetivamente garantam o direito à educação de qualidade.

Para além da divulgação dos dados, da responsabilização e da criação de um ethos competitivo entre as escolas, a avaliação externa precisa integrar medidas de operacionalização, ou seja, ações políticas de intervenção no funcionamento das escolas e na gestão do sistema, dando, desta forma, sentido mais amplo e menos reducionista, lançando um olhar integrador de todas as dinâmicas que fazem parte da qualidade, mas que são muitas vezes desconsideradas pelos instrumentos de avaliação.

É preciso integrar os resultados do desempenho escolar com os contextos ou dinâmicas intra e extraescolares, na medida em que esta integração dará condições para a gestão escolar traçar suas próprias metas e estratégias, e definir intervenções alicerçadas na democratização e na autonomia, sem que isso signifique realizar manobras pedagógicas para atender as metas pré-estabelecidas pelo índice.

O que o Estado entende como qualidade na educação está relacionado apenas a conhecimentos e habilidades passíveis de serem mensurados via testes 
padronizados, pois a política empreendida pelo Estado, ao estabelecer o IDEB como referencial de qualidade, pautou-se numa dimensão generalizada e global de educação, sem levar em consideração as peculiaridades de cada região, de cada município e de cada escola, assim como seus contextos e especificidades. Uma das perspectivas para que isso ocorra efetivamente é aliar a avaliação externa à autoavaliação da escola.

Para finalizar, consideramos que a qualidade ainda é o grande desafio da educação brasileira, porém, enquanto não forem considerados a clientela e os contextos próprios em que cada "educação" se faz, o país periga continuar a formar alunos capazes de realizar as provas das avaliações externas, mas incapazes de mobilizar conhecimentos em situações reais.

\section{Referências}

AFONSO, A. J. Avaliação educacional: regulação e emancipação: para uma sociologia das políticas contemporâneas. 3. ed. São Paulo: Cortez, 2005.

ALMEIDA, L. C.; DALBEN, A.; FREITAS, L. C. O Ideb: limites e ilusões de uma política educacional. Educação e Sociedade, Campinas, v. 34, n. 125, p. 1153-1174, 2013.

ARAÚJO, C. H.; LUZIO, N. Avaliação da Educação Básica: em busca da qualidade e equidade no Brasil. Brasília: Instituto Nacional de Estudos e Pesquisas Educacionais Anísio Teixeira, 2005.

AZEVEDO, J. C. Educação pública: o desafio da qualidade. Estudos Avançados, São Paulo, v. 21, n. 60, p. 7-26, 2007. Disponível em: <http://www.scielo.br/pdf/ ea/v21n60/a02v2160.pdf>. Acesso em: 2 dez. 2010.

BALL, S. J. Diretrizes políticas globais e relações políticas locais em educação. Currículo sem Fronteiras, [S.1.], v. 1, n. 2, p. 99-116, jul./dez. 2001.

BRASIL. Decreto n ${ }^{\circ}$ 6.094, de 24 de abril de 2007. Dispõe sobre a implementação do Plano de Metas Compromisso Todos pela Educação, pela União Federal, em regime de colaboração com municípios, Distrito Federal e Estados, e a participação das famílias e da comunidade, mediante programa e ações de assistência técnica e financeira, visando a mobilização social pela melhoria da 
qualidade da educação básica. Diário Oficial [da] República Federativa do Brasil, Brasília, DF, 25 abr. 2007.

. Instituto Nacional de Estudos e Pesquisas Educacionais Anísio Teixeira - Inep. Consulta ao Índice de Desenvolvimento da Educação Básica. Disponível em: <http://ideb.inep.gov.br/>. Acesso em: 3 fev. 2013.

. Ministério da Educação. Lei no 4.024 de 20 de dezembro de 1961. Lei de Diretrizes e Bases da Educação Nacional. . Diário Oficial [da] República Federativa do Brasil, Brasília, DF, 27 dez. 1961.

BRUNO, L. Educação, qualificação e desenvolvimento econômico. In: BRUNO, L. (Org.). Educação e trabalho no capitalismo contemporâneo: leituras selecionadas. São Paulo: Atlas, 1996.

CASTRO, A. M. D. A. A qualidade da educação básica e a gestão da escola. In: FRANÇA, M.; BEZERRA, M. C. (Org.). Política educacional: gestão e qualidade do ensino. Brasília: Líber, 2009.

CHIRINÉA, A. M. O índice de desenvolvimento da educação básica (IDEB) e as dimensões associadas à qualidade da educação na escola pública municipal. 2010. 121 f. Dissertação (Mestrado em Educação)-Universidade Estadual Paulista "Júlio de Mesquita Filho", Faculdade de Filosofia e Ciências, Marília, 2010.

COELHO, M. I. M. Vinte anos de avaliação da educação básica no Brasil: aprendizagens e desafios. Ensaio: Avaliação e Políticas Públicas em Educação, Rio de Janeiro, v. 16, n. 59, p. 229-258, abr.jun. 2008.

FERNANDES, R. Índice de Desenvolvimento da Educação Básica (Ideb). Brasília: Instituto Nacional de Estudos e Pesquisas Educacionais Anísio Teixeira, 2007.

FRANCO, C; ALVES, F; BONAMINO, A. Qualidade do Ensino Fundamental: políticas, suas possibilidade, seus limites. Educação \& Sociedade, Campinas, v. 28 , n. 100, p. 989-1014, 2007.

FREITAS, L. C. Eliminação adiada: o caso das classes populares no interior da escola e a ocultação da (má) qualidade do ensino. Educação \& Sociedade, Campinas, v. 28, n. 100, p. 965-987, 2007. 
HADDAD, F. O Plano de Desenvolvimento da Educação: razões, princípios e programas. Brasília: Instituto Nacional de Estudos e Pesquisas Educacionais Anísio Teixeira, 2008.

HORTA NETO, J. L. Um olhar retrospectivo sobre a avaliação externa no Brasil: das primeiras medições em educação até o SAEB de 2005. Revista Iberoamericana de Educación, Madrid, v. 42, p. 1-14, 2007. Disponível em:<http://www.rieoei. org/deloslectores/1533Horta.pdf>. Acesso em: 2 ago. 2009.

LIMA, L. C. A escola como organização educativa: uma abordagem sociológica. 3. ed. São Paulo: Cortez, 2008.

NÓVOA, A. (Org.). As organizações escolares em análise. Lisboa: Dom Quixote, 1995.

OLIVEIRA, D. A. A qualidade total na educação: os critérios da economia privada na gestão da escola pública. In: BRUNO, L. (Org.). Educação e Trabalho no Capitalismo Contemporâneo: leituras selecionadas. São Paulo: Atlas, 1996.

OLIVEIRA, J. B. A.; SCHWARTZMAN, S. A Escola vista por dentro. Belo Horizonte: Alfa Educativa, 2002.

OLIVEIRA, R. P.; ARAÚJO, G. C. Qualidade do ensino: uma nova dimensão da luta pelo direito à educação. Revista Brasileira de Educação, São Paulo, n. 28, p. 5-23, jan./abr. 2005.

PARO, V. H. Escritos sobre educação. São Paulo: Xamã, 2001.

PINTO, J. M. R. O custo de uma educação de qualidade. In: CORREA, B. C.; GARCIA, T. O. (Org.). Política educacionais e organização do trabalho na escola. São Paulo: Xamã, 2008.

SILVA, I. F. O sistema nacional de avaliação: características, dispositivos legais e resultados. Estudos em Avaliação Educacional, São Paulo, v. 21, n. 47, p. 427-448, set/dez. 2010.

SOUSA, S. Z; OLIVEIRA, R. P. Sistemas estaduais de Avaliação: uso dos resultados, implicações e tendências. Cadernos de Pesquisa, São Paulo, v. 40, n. 141, dez. 2010. 
SOUZA, S. M. Z. L. Avaliação do rendimento escolar como instrumento de gestão educacional. In: OLIVEIRA, Dalila Andrade. Gestão democrática da educação: desafios contemporâneos. 3. ed. Petrópolis: Vozes, 1997. p. 264-283.

SOUZA, S. Z. L; OLIVEIRA, R. P. Políticas de avaliação da educação e quase mercado no Brasil. Educação \& Sociedade, Campinas, v. 24, n. 84, p. 873-895, 2003.

WERLE, F. O. C. Políticas de avaliação em larga escala na educação básica: do controle de resultados à intervenção nos processos de operacionalização do ensino. Ensaio: Avaliação e Políticas Públicas em Educação, Rio de Janeiro, v. 19, n. 73, p. 769-792, 2011.

\section{The IDEB as state regulatory policy and legitimation of quality: in search of meaning Abstract}

This paper discusses the quality of basic education legitimized by the external evaluation and publicized by the Basic Education Development Index (IDEB) - an index that combines the performance of students in the assessment and the school flow, culminating with the establishment of an objective parameter (grade) that aims to reflect the Brazilian educational quality. The arguments are based on the premise that these two elements are incipient to determine the quality of education in the country without taking into account other factors that affect quality, namely: socio-economic and cultural level of the students, teacher training, enhancement of teaching, tangible and intangible working conditions, school management, school infrastructure, supplies, etc. The reflection leading to the debate on the lack of evidence to establish the quality of education travels the ways of the external evaluation in Brazil, the technical rationality of the school management referenced primarily by the IDEB and its governance to achieve the goals determined by this index. The purpose of this essay is to contribute to the current debate on the IDEB as a proposer and mobilizer of policies for the Brazilian public schools.

Keywords: Management. Public school. Educational quality. External evaluation. 


\section{IDEB como política de regulación estatal y legitimación de la calidad: en busca de sentido Resumen}

Este trabajo analiza la calidad de la educación básica legitimada por la evaluación externa y publicada por el Índice de Desarrollo de la Educación Básica (IDEB). Índice que combina el rendimiento de los estudiantes en la evaluación y el flujo de la escuela, que culminó con el establecimiento de un parámetro objetivo (nota) cuyo objetivo es reflejar la calidad de la educación brasileña. Los argumentos basados en la premisa de que estos dos elementos son incipientes para determinar la calidad de la educación en el país, sin tener en cuenta otros factores que afectan a la calidad, a saber: el nivel socioeconómico y cultural de los estudiantes, la formación del profesorado, la mejora de enseñanza $y$ de las condiciones tangibles e intangibles de trabajo, la gestión escolar, la infraestructura escolar, los insumos, etc. La reflexión que permita el debate sobre la falta de pruebas para establecer la calidad de la educación, recorre los caminos de la evaluación externa en Brasil, de la racionalidad técnica en gestión escolar referida principalmente por IDEB y su gobernabilidad para alcanzar los objetivos determinados por el índice. Con este ensayo se busca contribuir al debate actual sobre el IDEB como elemento impulsor y movilizador de políticas en las escuelas públicas brasileñas.

Palabras-clave: Gestión. Escuela pública. Calidad educativa. Evaluación externa.

\section{Informações dos autores}

Andréia Melanda Chirinéa: Professora da educação básica e do ensino superior. Doutoranda em Educação. Contato: andreia.melanda@gmail.com

Carlos da Fonseca Brandão: Professor Adjunto. Doutor em Educação. Contato: cbrandao@assis.unesp.br 